\title{
Cellulose fiber-reinforced high-density polyethylene composites-Mechanical and thermal properties
}

\author{
Daniella R Mulinari', Herman JC Voorwald ${ }^{2}$, \\ Maria OH Cioffi ${ }^{2}$ and Maria LCP da Silva ${ }^{3}$
}

\begin{abstract}
In this investigation, the thermal and mechanical properties of cellulose fibers from sugarcane bagasse reinforced with high density polyethylene composites were evaluated. Cellulose fibers were modified with hydrous $\mathrm{Zr}$ oxide to clean the fiber surface and improve the fibers-matrix adhesion. Composites were manufactured using a thermokinetic mixer process and the fiber content was responsible for 5, 10, 20, 30, and 40wt\% in the composition. The chemical modification of the cellulose fibers with zirconium oxide was verified by FTIR analysis and the fibers' morphological aspects by SEM. After the chemical modification, the FTIR results showed reduction of $\mathrm{OH}$ bonds. SEM characterization showed that the modification changed the morphology of fibers. The results show that composites reinforced with modified cellulose fibers have an improvement in the thermal and mechanical properties, when compared to the non-cellulose fibers. In addition, an enhancement on the mechanical properties of composites was found, i.e. a gain of $122.4 \%$ compared to neat polymer at $40 \mathrm{wt} . \%$ fiber loading in Young's modulus. The thermal properties show a slight decrease with increase of modified cellulose.
\end{abstract}

\section{Keywords}

Sugarcane bagasse, cellulose, composite, $\mathrm{ZrO}_{2} \cdot \mathrm{nH}_{2} \mathrm{O}$, thermal properties, mechanical properties

\section{Introduction}

Many questions on sustainable development have emerged due to the risk of exhaustion of non-renewable raw materials, and emissions of greenhouse gases. So, natural fibers have been evaluated as environmentfriendly materials. Thus, the interest in composite materials reinforced with natural fibers increased considerably due to new environmental legislation and consumer pressure has forced manufacturing industries to search materials that can substitute conventional nonrenewable materials such as glass and carbon fibers. In recent years, interest in natural fibers has increased worldwide due to their characteristics. ${ }^{1-4}$

Omrani et al. ${ }^{5}$ reported on natural fiber-reinforced composites with special reference to the type of fibers, matrix polymers, treatment of fibers, and test parameters, and the results show that composites reinforced with natural fibers have an improvement in tribological properties and their properties are comparable with conventional fibers.
Barari et al. ${ }^{6}$ studied that the plant-derived cellulose nano-fibers (CNFs)/bio-based epoxy composites were manufactured using the Liquid Composite Molding (LCM) process and the results indicated that the manufactured composites showed improved mechanical and tribological properties when compared to the pure epoxy samples. Brazil has a large range of natural resources, including natural fibers from several sources, such as banana, coconuts, sugarcane bagasse, cotton, sisal, and curaua. ${ }^{7-9}$

Natural fibers, compared with glass fibers, exhibit better specific mechanical properties, such as stiffness, impact resistance, flexibility and modulus. ${ }^{10-12}$

\footnotetext{
'Department of Mechanical and Energy, FAT/UERJ, Brazil

${ }^{2}$ Department of Materials and Technology, UNESP/FEG, Brazil

${ }^{3}$ Department of Chemical Engineering, EEL/USP, Brazil

Corresponding author:

Daniella R Mulinari, Department of Mechanical and Energy, FAT/UERJ, Resende/RJ, Brazil.

Email: dmulinari@hotmail.com.br
} 
Other desirable properties, related to processing, include lower equipment abrasion and lower energy consumption. In addition, natural fibers are biodegradable and some can be produced on a large scale without displacement of other crops. For these reasons, natural fiber composites have been used in many applications such as architectural materials and in the automotive industry. ${ }^{13}$

However, they also present disadvantages such as incompatibility between fibers and polymer matrices, the tendency to form aggregates during processing, processing permissible temperature which does not collaborate to reinforce the polymer and the poor resistance to moisture, reducing the use of natural fibers as reinforcement in polymers. The incompatibility of components is responsible for poor thermal and mechanical properties. ${ }^{14}$

However, many studies have been aimed to improve the adhesion between fibers and matrix, such as bleaching, acetylation, etherification, estherification, alkali treatment and others. ${ }^{15-19}$

Another important point is the processing temperature, which must be maintained below $200^{\circ} \mathrm{C}$ to avoid negative influence on properties due to the natural fibers' degradation. ${ }^{20}$ High density polyethylene, with melting point of about $120-140^{\circ} \mathrm{C}$ can be processed at temperatures in the range of $140-200^{\circ} \mathrm{C} .{ }^{21}$ The thermal dimensional stability of a material is a desirable property in many applications, especially when combining different materials. ${ }^{22}$

In this study, cellulose fibers from sugarcane bagasse modified with zirconium oxide and reinforced with high density polyethylene were selected to improve their thermal and mechanical properties. This type modification made in the cellulose fibers have also been used for specific applications such as: $\mathrm{TiO}_{2}$ for bactericidal activities and reinforcement in polymers matrixes, $\mathrm{ZrO}_{2}$ for retention and analysis of $\mathrm{Cr}(\mathrm{VI})$ and for adsorption of sulfate ions. ${ }^{23-26}$

\section{Methods}

Cellulose fibers from sugarcane bagasse were obtained according to Mulinari and Da Silva. ${ }^{26}$ The length and diameter values are $100-500 \mu \mathrm{m}$ and $10-30 \mu \mathrm{m}$, respectively.

The chemical structure of cellulose fibers and cellulose fibers modified with hydrous $\mathrm{Zr}$ oxide from sugarcane bagasse was evaluated by FTIR spectrophotometer (Perkin Elmer). The samples were prepared by mixing the materials and $\mathrm{KBr}$ in the proportion 1:200 $(\mathrm{w} / \mathrm{w})$. For all spectra, 16 scans were accumulated with a $4 \mathrm{~cm}^{-1}$ resolution. SEM micrographs of non-modified and modified cellulose fibers were obtained using a JEOL JSM5310 field emission scanning electron microscope, operated at $15 \mathrm{kV}$. Prior to SEM evaluation, the specimen was coated using gold sputtering.

\section{Composites preparation}

Cellulose fibers from sugarcane bagasse modified and non-modified were mixed with the HDPE in a thermokinetic mixer, model $\mathrm{MH}-50 \mathrm{H}$, with speed rate maintained at $5250 \mathrm{r} / \mathrm{min}$, in which fibers were responsible for $5,10,20,30$, and $40 \mathrm{wt} \%$ in the composition. After the mixture, composites were dried and ground in mill. Composites and pure HDPE were placed in an injector camera at $165^{\circ} \mathrm{C}$ and $2{ }^{\circ} \mathrm{C} \min ^{-1}$ heating rate in a required dimension pre-warm mold to obtain tensile specimens.

\section{Mechanical properties}

Composites were analyzed in an "EMIC" universaltesting machine (model DL10000) equipped with pneumatic claws. For tensile tests, five specimens of composites were analyzed, with dimensions in agreement with the ASTM D 638 standard: $19 \mathrm{~mm}$ width, $165 \mathrm{~mm}$ length and $3 \mathrm{~mm}$ thickness at $2 \mathrm{~mm} \mathrm{~min}^{-1}$ cross-head speed.

In the flexural tests, a load was applied on the specimen at $1.3 \mathrm{~mm} \mathrm{~min}^{-1}$ crosshead motion rate. Five specimens were analyzed with dimensions in agreement with the ASTM D 790 standard: $25 \mathrm{~mm}$ width, $76 \mathrm{~mm}$ length, and $3.2 \mathrm{~mm}$ thickness. The adopted flexural test was the 3-points method.

Impact test of the composites were analyzed in a "pantec" machine (model 30), and five specimens of composites were analyzed, with dimensions in agreement with the ASTM D 6110 standard: $12 \mathrm{~mm}$ width, $55 \mathrm{~mm}$ length and $6 \mathrm{~mm}$ thickness.

\section{Thermogravimetric analysis (TGA and DSC)}

Samples used for the thermogravimetric analysis were cut from the mixture materials in order to have a weight of $10 \mathrm{mg}$. Furthermore, specimens were dried in an oven for $1 \mathrm{~h}$ at $100^{\circ} \mathrm{C}$. TGA was carried out using a SHIMADZU (TGA-50) instrument, in $\mathrm{N}_{2}$ atmosphere at $10^{\circ} \mathrm{C} \mathrm{min}{ }^{-1}$ heating rate, from 30 to $650^{\circ} \mathrm{C}$.

\section{Results and discussion}

\section{Fibers analysis}

Infrared spectra of cellulose fibers from sugarcane bagasse without and with modification are displayed in Figure 1.

Table 1 summarizes higher bands observed in the FTIR spectrum of cellulose fibers from sugarcane 


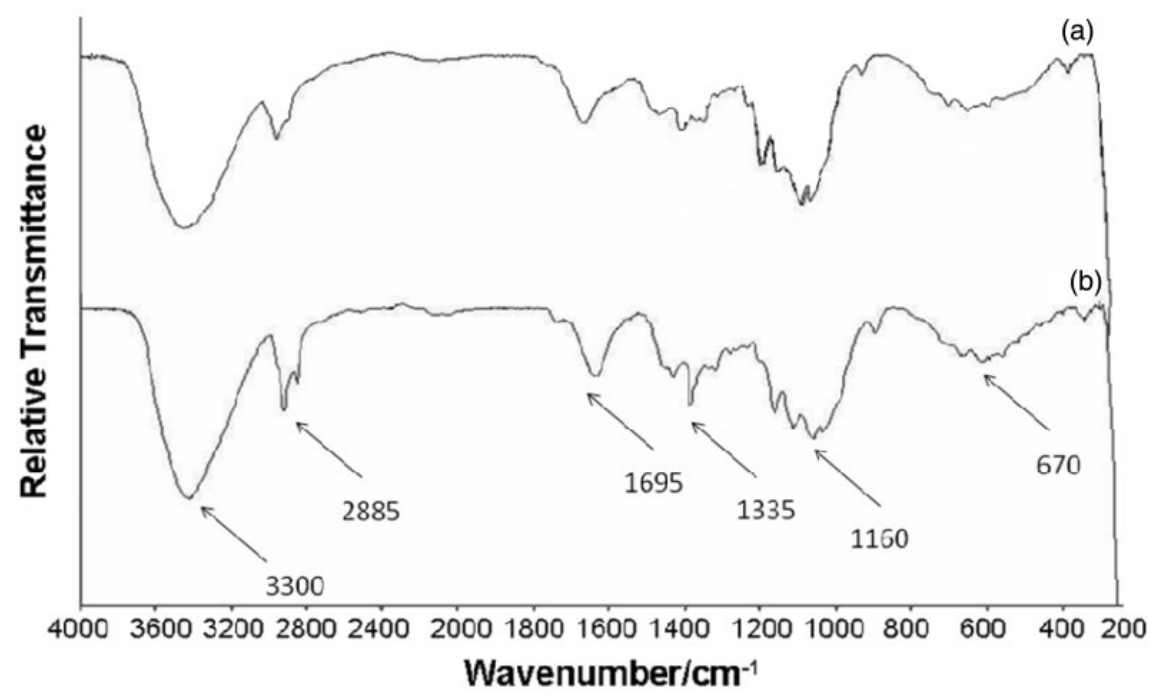

Figure I. FTIR spectra of sugarcane bagasse (wavenumber $4000-400 \mathrm{~cm}^{-1}$ ): non-modified cellulose (a) and modified cellulose fibers (b).

Table I. Infrared main transitions for sugarcane bagasse.

\begin{tabular}{lll}
\hline $\begin{array}{l}\text { Wavenumber } \\
\left(\mathrm{cm}^{-1}\right)\end{array}$ & Vibration & Source \\
\hline 3300 & O-H linked shearing & Polysaccharides \\
2885 & C-H symmetrical stretching & Polysaccharides \\
$1650-1630$ & OH (water) & Water \\
1335 & C-O aromatic ring & Cellulose \\
1162 & C-O-C asymmetrical & Cellulose \\
& stretching & \\
670 & C-OH out-of-plane bending & Cellulose
\end{tabular}

bagasse and their assignments to chemical group vibrations and molecules.

The most visible differences between the spectra of non-modified cellulose fibers and $\mathrm{Cell} / \mathrm{ZrO}_{2} \cdot \mathrm{nH}_{2} \mathrm{O}$ are the modifications of the signal at $2885 \mathrm{~cm}^{-1}$ and $1732 \mathrm{~cm}^{-1}$, characteristics of the stretching of symmetrical $\mathrm{CH}$ groups and stretching of unconjugated $\mathrm{CO}$ groups present in polysaccharides and xylans. Considering the first region, the ratio between intensity of the $\mathrm{C}-\mathrm{H}$ stretching band $\left(\sim 2900 \mathrm{~cm}^{-1}\right)$ is lower in the spectrum of the $\mathrm{Cell} / \mathrm{ZrO}_{2} \cdot \mathrm{nH}_{2} \mathrm{O}$ material than that observed for the non-modified cellulose fibers. On the other hand, at the second region it may be observed modifications, especially in the ratio between the intensities of the $\mathrm{C}=\mathrm{O}$ stretching band $\left(\sim 1730 \mathrm{~cm}^{-1}\right)$.

The SEM evaluations were applied for cellulose fiber characterization before and after chemical modification with hydrous zirconium oxide. Cellulose fibers are shown in Figure 2(a), which evidence fibers of flattened forms and different sizes. The length and diameter values are $100-500 \mu \mathrm{m}$ and $10-30 \mu \mathrm{m}$, respectively. In the modification of fibers, it is noted a large area and roughness on the surface according to Figure 3.

\section{Thermogravimetry analysis}

The thermogravimetric results of HDPE, and modified and non-modified cellulose fibers show distinct process of weight loss occurring at different temperatures. Figures 4 to 6 show TGA curves of HDPE, modified and non-modified cellulose fibers, and cellulose fibers/HDPE composites (5 and $40 \mathrm{wt} \%$ ). For HDPE, there is only one-step decomposition process, while the cellulose fibers and composites show two-step processes.

From the TGA curves, it is possible to observe the starting of modified and non-modified cellulose fibers' weight loss at $300^{\circ} \mathrm{C}$ (Figure 4). The first process of weight loss of the modified and non-modified cellulose fibers is attributed to thermal degradation of fibers. The next weight loss is associated to decomposition of the $\alpha$-cellulose present in the fibers. Araújo et al. ${ }^{20}$ observed similar behavior with the curaua fibers.

HDPE started decomposition at about $430^{\circ} \mathrm{C}$, which was higher in comparison to fibers, Figure 4. On the other hand, composites presented intermediary thermal stability between fibers and matrix, showing synergistic interactions. The addition of fibers decreased the thermal stability of the composites, Figures 5 and 6 .

Table 2 shows the weight loss and degradation temperature peak of composites, HDPE, and modified and non-modified cellulose fibers.

Table 2 shows that all the composites have lost less than $10 \%$ of their weight up to $270^{\circ} \mathrm{C}$, which is 
(a)

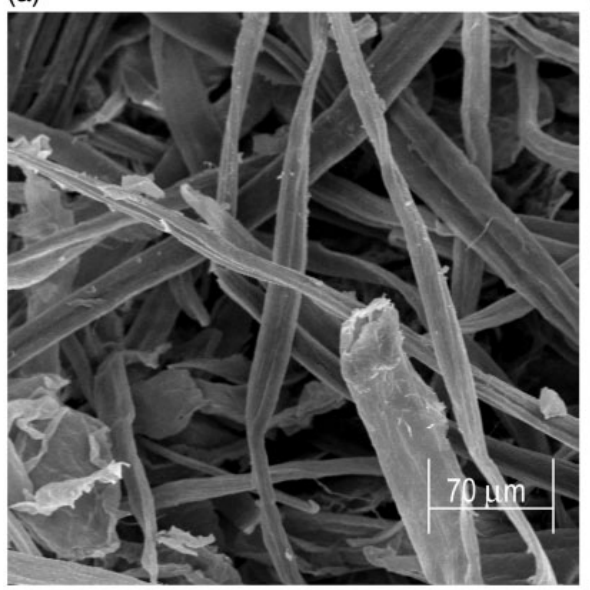

(b)

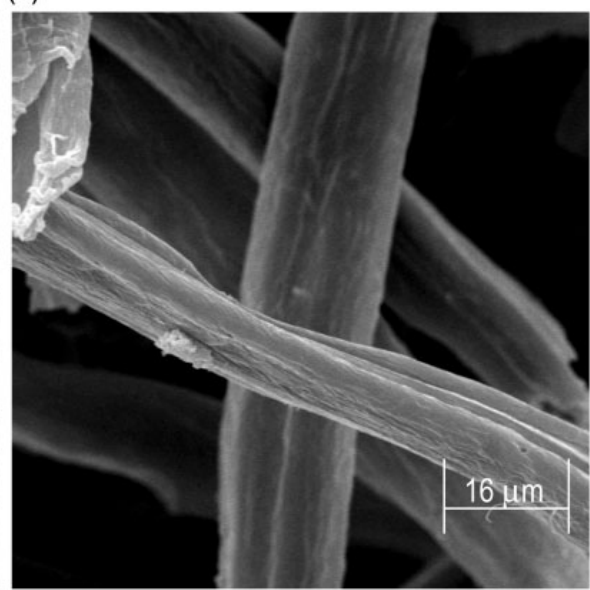

Figure 2. Morphology of cellulose fibers non-modified: (a) $500 \times$ and (b) $2000 \times$.

(a)

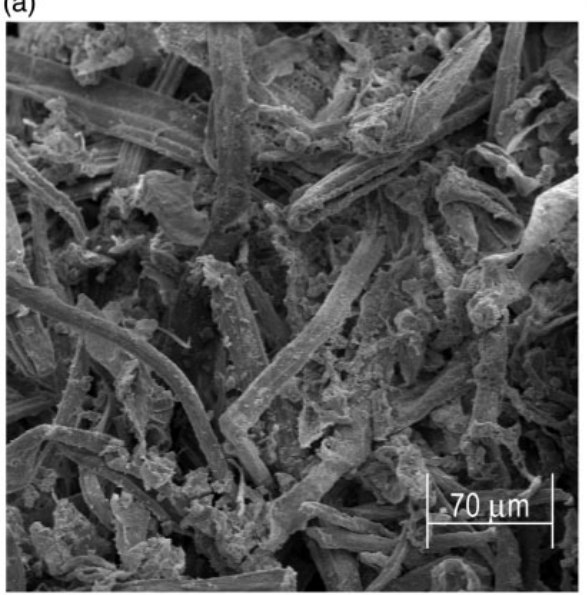

(b)

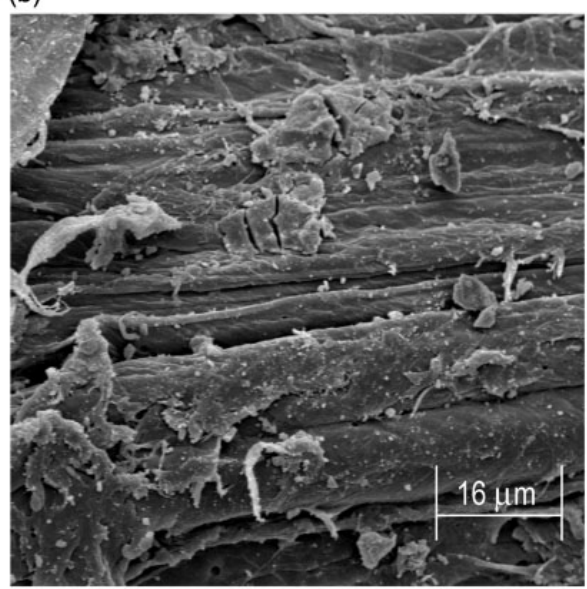

Figure 3. Morphology of cellulose fibers modified: (a) $500 \times$ and (b) $2000 \times$.

sufficient for their melt processing. It is worth noting that about $8 \%$ of this weight loss was released up to $100^{\circ} \mathrm{C}$, representing the adsorbed water. The small differences detected above $300^{\circ} \mathrm{C}$ (see detail in Figures 5 and 6) can be correlated with the thermal stability of the fibers. Thus, reinforcement decreases the thermal stability of the composite.

It is also observed that high density polyethylene practically did not lose weight at $400^{\circ} \mathrm{C}$; however, from $450^{\circ} \mathrm{C}$ on, the weight loss was fast and accentuated, resulting in minimum residue. HDPE started decomposition at about $434^{\circ} \mathrm{C}$ (indicates the degradation of saturated and unsaturated carbon atoms in high density polyethylene), which was higher than that for fibers. In this same temperature around, the addition of fibers decreased the thermal stability of the composite, but modified cellulose fiber-reinforced HDPE composites presented higher thermal stability than the non-modified cellulose fiber-reinforced HDPE composites (at $400^{\circ} \mathrm{C}$ ). One explanation for this fact is that the modified cellulose fiber-reinforced HDPE composites presented more interfacial interaction due to modification on the fibers surfaces. The modified cellulose fibers with hydrous zirconium oxide can be described by equation (1)

$$
\mathrm{mCellOH}+\mathrm{MX}_{\mathrm{n}} \rightarrow(\mathrm{CellO})_{\mathrm{m}} \mathrm{MX}_{\mathrm{n}-\mathrm{m}}+\mathrm{mHX}
$$

where $\mathrm{MX}_{\mathrm{n}}$ is an active metal compound and CellOH corresponds to the hydroxyls groups.

Hydrolysis leads to the formation of oxide monolayer, where the metals are incorporated to the surface through CellO-M bond. The hydrolysis reaction is 


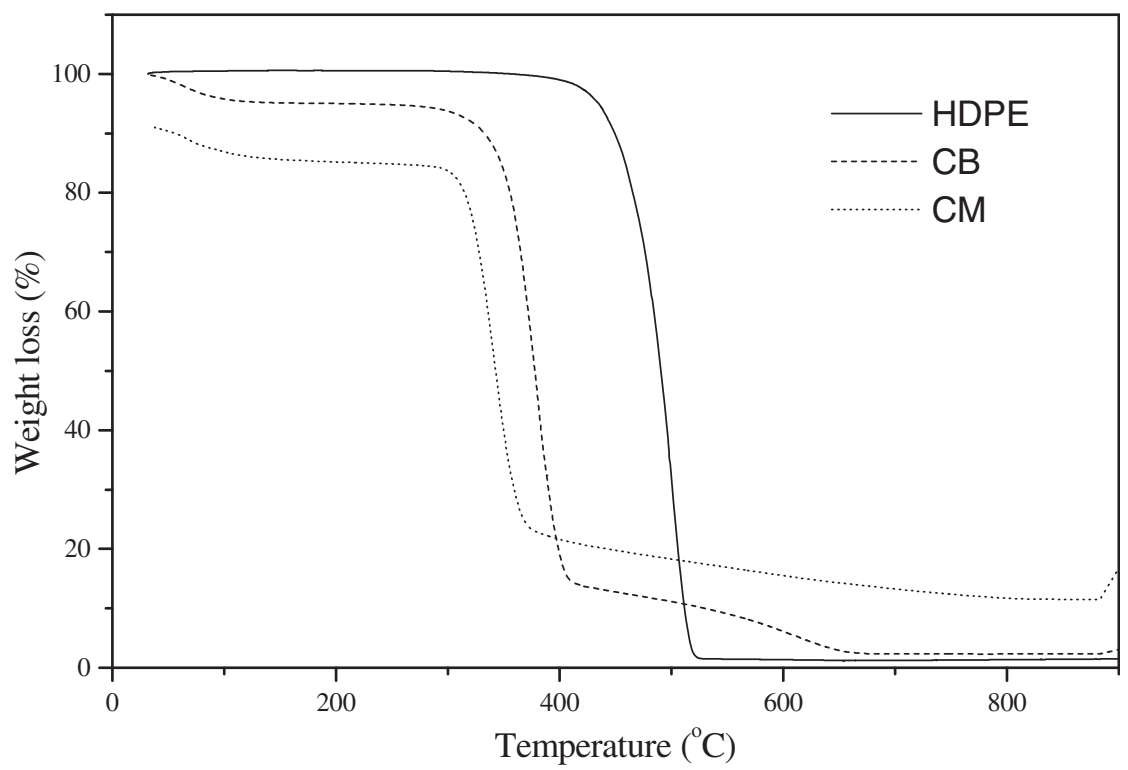

Figure 4. TGA curves of HDPE and cellulose fibers non-modified (CB) and cellulose fibers modified (CM).

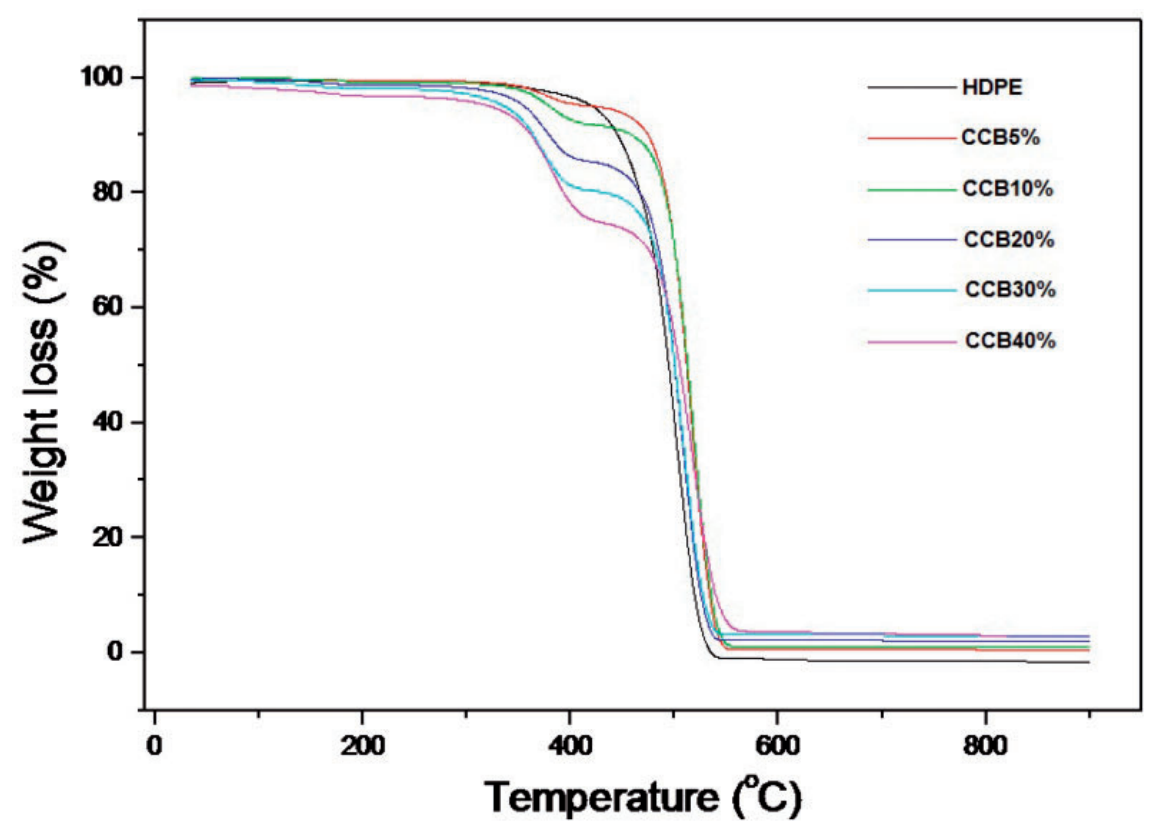

Figure 5. TGA curves of HDPE and CB composites.

shown in equation (2).

$$
\begin{aligned}
& (\mathrm{CellO})_{\mathrm{m}} \mathrm{MX}_{\mathrm{n}-\mathrm{m}}+(\mathrm{n}-\mathrm{m}) \mathrm{H}_{2} \mathrm{O} \rightarrow(\mathrm{CellO})_{\mathrm{m}} \mathrm{M}(\mathrm{OH})_{\mathrm{n}-\mathrm{m}} \\
& \quad+(\mathrm{n}-\mathrm{m}) \mathrm{HX}
\end{aligned}
$$

Figure 7 shows the schematic reaction representation of the Lewis acid with the cellulose. ${ }^{26}$ The reaction is carried out under anhydrous conditions in the first step because it is supposed that primarily a donor-acceptor bond is formed between $\mathrm{ZrO}_{2} \cdot \mathrm{nH}_{2} \mathrm{O}$ and the oxygen of the $\mathrm{C}^{1}-\mathrm{O}-\mathrm{C}^{5}$ and $\mathrm{C}^{1}-\mathrm{O}-\mathrm{C}^{4}$ bonds. The attack to the former oxide bond leads to a ring opening and provides a molecule rupture process in order to form micro fibers. Ammonium solution is a required mean to promote the chemical link of metallic oxide with fibers surfaces.

\section{Mechanical properties}

The addition of cellulose fibers (modified and non-modified) to the HDPE matrix resulted in 


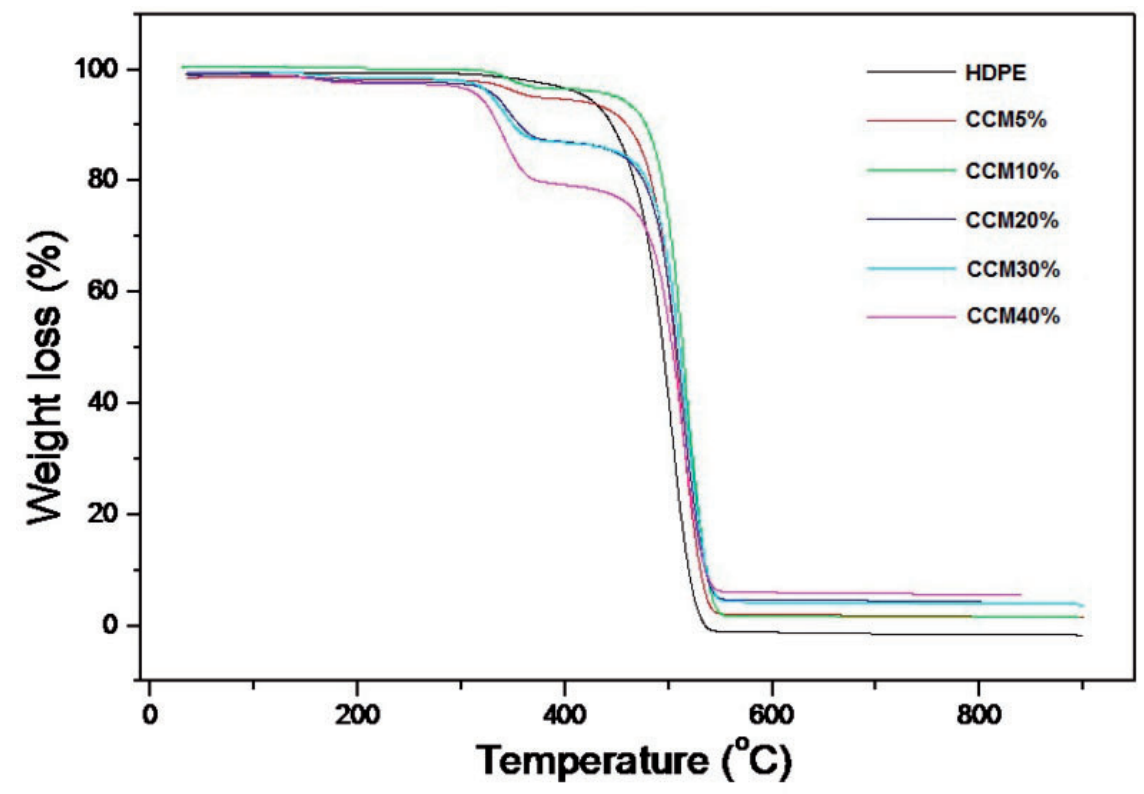

Figure 6. TGA curves of HDPE and CM composites.

Table 2. Thermal properties of the materials.

\begin{tabular}{|c|c|c|c|c|c|c|c|c|}
\hline \multirow{3}{*}{$\frac{\text { Samples }}{\text { HDPE }}$} & \multicolumn{6}{|c|}{ Weight loss (\%) } & \multirow{2}{*}{\multicolumn{2}{|c|}{$\begin{array}{l}\text { Degradation } \\
\text { temperature }\left({ }^{\circ} \mathrm{C}\right)\end{array}$}} \\
\hline & \multirow{2}{*}{$\frac{100^{\circ} \mathrm{C}}{0.65}$} & \multirow{2}{*}{$\frac{200^{\circ} \mathrm{C}}{0.65}$} & \multirow{2}{*}{$\frac{300^{\circ} \mathrm{C}}{0.74}$} & \multirow{2}{*}{$\frac{400^{\circ} \mathrm{C}}{3.33}$} & \multirow{2}{*}{$\frac{500^{\circ} \mathrm{C}}{59.7}$} & \multirow{2}{*}{$\frac{600^{\circ} \mathrm{C}}{98.7}$} & & \\
\hline & & & & & & & - & 434 \\
\hline $\mathrm{CB}$ & 4.3 & 5.1 & 6.4 & 81.2 & 88.9 & 93.9 & - & 335 \\
\hline CM & 13.1 & 14.8 & 16.3 & 78.4 & 81.7 & 84.5 & - & 312 \\
\hline CCB5\% & 0.0 & 0.5 & 0.6 & 4.3 & 26.7 & 99.4 & 365.0 & 476.0 \\
\hline CСBI0\% & 0.2 & 0.65 & 1.0 & 7.6 & 33.4 & 98.8 & 376.8 & 513.7 \\
\hline CСB20\% & 0.3 & 1.2 & 1.8 & 13.4 & 43.9 & 97.8 & 379.3 & 510.3 \\
\hline ССВ30\% & 0.6 & 1.8 & 2.7 & 18.4 & 45.2 & 96.8 & 375.6 & 511.2 \\
\hline CCB40\% & 1.9 & 3.2 & 4.2 & 22.8 & 49.1 & 96.4 & 377.7 & 512.7 \\
\hline CCM $5 \%$ & 1.3 & 1.7 & 19 & 5.3 & 39.8 & 98.0 & 347.1 & 510.4 \\
\hline CCMI0\% & 0.8 & 1.0 & 1.2 & 4.7 & 28.2 & 98.2 & 345.2 & 516.6 \\
\hline CCM $20 \%$ & 1.05 & 2.1 & 2.5 & 13.0 & 39.1 & 95.3 & 346.4 & 513.4 \\
\hline ССМ30\% & 0.5 & 1.5 & 2.0 & 13.1 & 35.4 & 95.7 & 339.3 & 515.5 \\
\hline CCM $40 \%$ & 0.8 & 2.4 & 3.2 & 20.7 & 45.6 & 94.0 & 340.0 & 511.8 \\
\hline
\end{tabular}

$\mathrm{CB}$, cellulose fibers non-modified; $\mathrm{CM}$, cellulose fibers modified; $C C B \%$, HDPE composites reinforced with cellulose fibers non-modified \%wt; CCM\%, HDPE composites reinforced with cellulose fibers modified \%wt.

changes of the mechanical properties, which are shown in Table 3.

The increase in the fiber content from 0 to $40 \mathrm{wt} . \%$ resulted in a twofold increase in the Young's modulus, from $732.5 \mathrm{MPa}$ of neat HDPE to $1629 \mathrm{MPa}$ when $40 \mathrm{wt} . \%$ fiber is added. A significant increase in the modulus can be observed with increasing fibers content. ${ }^{25}$ Cellulose fibers modified may exhibit greater interactions with the polymer matrix, resulting in a good dispersion in the composite. This fact occurred due to modification of the fibers, which decreases the effective interfacial tension between fibers and the polymer chains leading to better interaction and properties.

Another result that is observed is the progressive decrease in elongation at break of composites compared to pure HDPE. This decrease on the elongation may be attributed to a reduction in deformability of the rigid interface between fibers and matrix. ${ }^{25}$ 




Figure 7. Reaction of the Lewis acid with cellulose and formation of the donor-acceptor bond. ${ }^{27}$

Table 3. Mechanical properties of the composite materials.

\begin{tabular}{lllllll}
\hline Samples & $\begin{array}{l}\text { Elongation at } \\
\text { break }(\%)\end{array}$ & $\begin{array}{l}\text { Tensile } \\
\text { strength } \\
(\mathrm{MPa})\end{array}$ & $\begin{array}{l}\text { Tensile } \\
\text { modulus } \\
(\mathrm{MPa})\end{array}$ & $\begin{array}{l}\text { Flexural } \\
\text { strength } \\
(\mathrm{MPa})\end{array}$ & $\begin{array}{l}\text { Flexural } \\
\text { modulus } \\
(\mathrm{MPa})\end{array}$ & $\begin{array}{l}\text { Impact } \\
\text { strength } \\
\left(\mathrm{kJ} . \mathrm{m}^{-2}\right)\end{array}$ \\
\hline HDPE & $8.9 \pm 0.8$ & $15.7 \pm 1.1$ & $732.5 \pm 90.6$ & $18.6 \pm 0.2$ & $794 \pm 17$ & $38.9 \pm 0.5$ \\
CCB5\% & $5.4 \pm 0.4$ & $16.2 \pm 0.7$ & $942.5 \pm 98.6$ & $18.8 \pm 0.4$ & $1002 \pm 32$ & $45.9 \pm 0.1$ \\
CCB10\% & $5.5 \pm 0.2$ & $15.6 \pm 0.3$ & $897 \pm 27.5$ & $20.1 \pm 0.7$ & $1107 \pm 35$ & $46.5 \pm 0.1$ \\
CCB20\% & $5.7 \pm 0.3$ & $15.8 \pm 0.3$ & $1141 \pm 62.5$ & $20.4 \pm 0.3$ & $1087 \pm 37$ & $48.0 \pm 0.2$ \\
CCB30\% & $6.0 \pm 0.7$ & $16.7 \pm 0.8$ & $1156 \pm 178$ & $21.9 \pm 1.4$ & $1176 \pm 65$ & $49.0 \pm 0.3$ \\
CCB40\% & $5.7 \pm 0.5$ & $16.8 \pm 1.3$ & $1217 \pm 191$ & $22.1 \pm 1.0$ & $1238 \pm 50$ & $50.6 \pm 0.1$ \\
CCM5\% & $7.2 \pm 0.1$ & $20.8 \pm 0.4$ & $1178 \pm 25$ & $18.8 \pm 0.7$ & $1294 \pm 94$ & $48.1 \pm 0.7$ \\
CCM10\% & $7.4 \pm 0.4$ & $21.9 \pm 0.6$ & $1238.5 \pm 41$ & $22.1 \pm 0.5$ & $1244 \pm 21$ & $50.0 \pm 0.1$ \\
CCM20\% & $6.5 \pm 0.2$ & $20.9 \pm 0.4$ & $1306 \pm 27$ & $21.3 \pm 0.5$ & $1241 \pm 40$ & $51.6 \pm 0.1$ \\
CCM30\% & $5.5 \pm 0.2$ & $19.9 \pm 0.4$ & $1490 \pm 71$ & $23.2 \pm 0.1$ & $1303 \pm 30$ & $52.4 \pm 0.1$ \\
CCM40\% & $5.9 \pm 0.4$ & $23.2 \pm 0.6$ & $1629 \pm 109$ & $23.1 \pm 1.7$ & $1304 \pm 97$ & $53.5 \pm 0.1$ \\
\hline
\end{tabular}

ССВ\%, HDPE composites reinforced with cellulose fibers non-modified \%wt; CCM\%, HDPE composites reinforced with cellulose fibers modified \%wt.

Similar behavior was described by Arrakhiz et al. ${ }^{28}$ to evaluate the mechanical and thermal properties of Pine cone fiber-reinforced compatibilized polypropylene.

Flexural properties of the composites were also influenced by amount of reinforcement embedded in the matrix. It was noted that the content of fibers reinforced in the matrix influenced the flexural strength and modulus when compared to pure HDPE, respectively. The flexural modulus of composites also increased from $0 \mathrm{wt} . \%$ to $40 \mathrm{wt} . \%$ fiber mass content. This increase may be explained by a better fibersmatrix interaction under the compressive stresses during bending, developed in the transverse section of the flexural specimens for whatever the surface condition of the fibers. ${ }^{29}$ In this work, $30 \mathrm{wt} . \%$ cellulose fibers-modified reinforced HDPE matrix was the optimum percentage to make the best flexural modulus.

It was observed similar results in impact tests. The insertion of fibers in the matrix caused an increase in the absorbed energy and consequently in the strength due to energy dissipation mechanism. This is probably due to the brittle behavior of fibers which limits the plasticity behavior of the composites compared to the neat polymer matrix. ${ }^{27}$ The fibers were pulled out from the matrix and dissipated energy during the mechanical friction process. Figure 8 shows the fracture of composites after tests, where it could be seen a fiber distribution uniformity in the matrix, broken fibers along the matrix and fibers pulled out (Figure 8(a) and (c) for non-modified), characterizing fragile breakage mechanism. Thus, from Figure 8(b) and (d) it was found that 
(a)



(c)

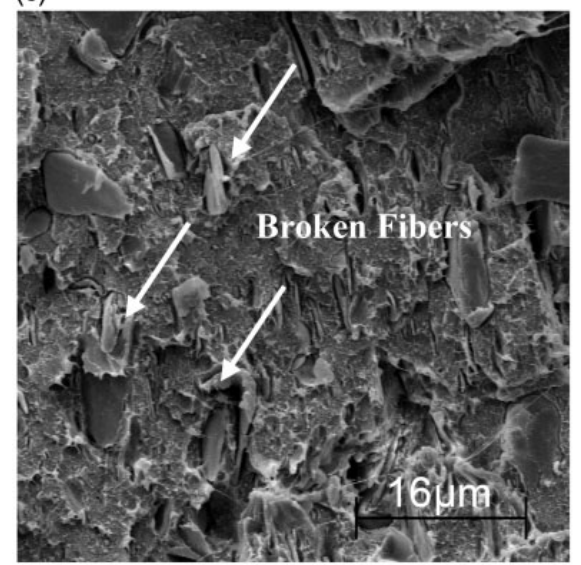

(b)

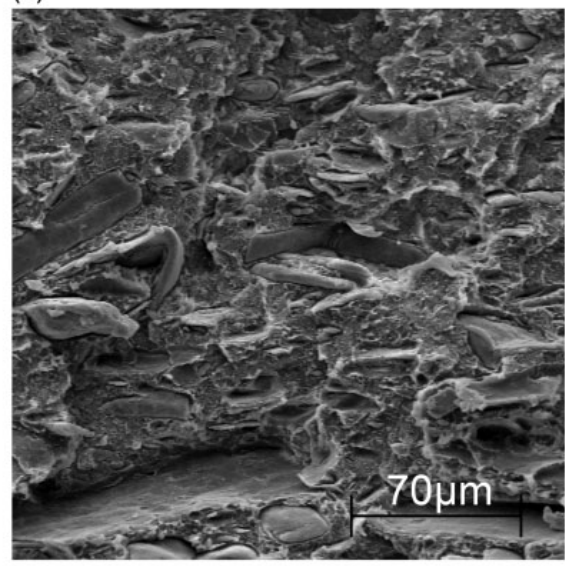

(d)

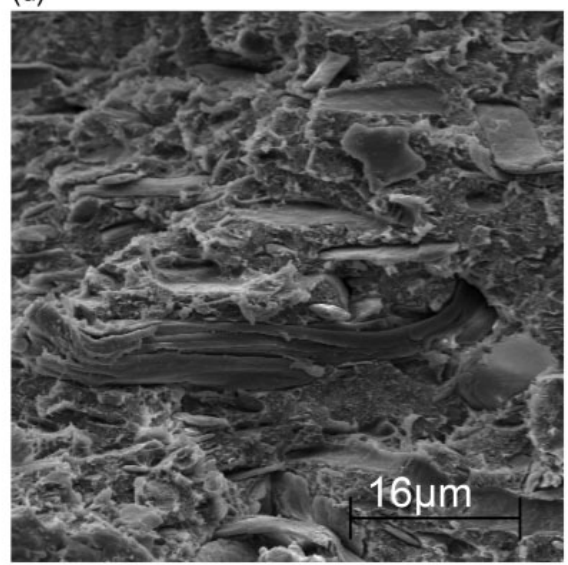

Figure 8. SEM of the composites after impact tests: (a) CB $30 \%$;

(b) CM 30\%; (c) CB 40\%; and (d) CM 40\%.

the modified cellulose fibers facilitated diffusion matrix to the interior of the fiber, increasing the impact resistance.

\section{Conclusions}

The objective of this study was to evaluate the benefits of reinforcing high density polyethylene with cellulose fibers modified with zirconium from sugarcane bagasse. The effect of zirconium oxide on cellulose fibers from sugarcane bagasse was confirmed by FTIR analysis and SEM. After the chemical modification, the FTIR results showed reduction of $\mathrm{OH}$ bonds. SEM characterization showed that the modification changed the morphology of fibers. The modification on cellulose fibers surfaces and composition affected the thermal stability and mechanical properties of the composites.

\section{Declaration of Conflicting Interests}

The author(s) declared no potential conflicts of interest with respect to the research, authorship, and/or publication of this article.

\section{Funding}

The author(s) disclosed receipt of the following financial support for the research, authorship, and/or publication of this article: the authors acknowledge CAPES for the financial support.

\section{References}

1. Kaewkuk S, Sutapun W and Jarukumjorn K. Effects of interfacial modification and fiber content on physical properties of sisal fiber/polypropylene composites. Compos Part B 2013; 45: 544-549.

2. Thakur VK and Thakur MK. Processing and characterization of natural cellulose fibers/thermoset polymer composites. Carbohyd Polym 2014; 109: 102-111.

3. Sena Neto AR, Araujo MAM, Souza FVD, et al. Characterization and comparative evaluation of thermal, structural, chemical, mechanical and morphological properties of six pineapple leaf fiber varieties for use in composites. Industrial Crops Prod 2013; 42: 529-537.

4. Essabir H, Hilali E, Elgharad A, et al. Mechanical and thermal properties of bio-composites based on polypropylene reinforced with Nut-shells of Argan particles. Mater Des 2013; 49: 442-448. 
5. Omrani E, Menezes PL and Rohatgi PK. State of the art on tribological behavior of polymer matrix composites reinforced with natural fibers in the green materials world. Eng Sci Technol, an International Journal 2015; 19: 717-736.

6. Barari B, Omrani E, Moghadam AD, et al. Mechanical, physical and tribological characterization of nano-cellulose fibers reinforced bio-epoxy composites: an attempt to fabricate and scale the 'Green' composite. Carbohydr Polym 2016; 147: 282-293.

7. Guimarães JL, Frollini E, Da Silva CG, et al. Characterization of banana, sugarcane bagasse and sponge gourd fibers of Brazil. Industrial Crops Prod 2009; 30: 407-415.

8. Pereira PHF, Rosa MF, Cioffi MOH, et al. Vegetal fibers in polymeric composites: a review. Polímeros 2015; 25: 9-22.

9. Spinacé MAS, Lambert CS, Karen KGF, et al. Characterization of lignocellulosic curaua fibres. Carbohydr Polym 2009; 77: 47-53.

10. Beckermann GW and Pickering KL. Engineering and evaluation of hemp fibre reinforced polypropylene composites: fibre treatment and matrix modification. Compos Part A 2009; 39: 979-988.

11. Müller CMO, Laurindo JB and Yamashita F. Effect of cellulose fibers on the crystallinity and mechanical properties of starch-based films at different relative humidity values. Carbohydr Polym 2009; 77: 293-299.

12. Wu C. Renewable resource-based composites of recycled natural fibers and maleated polylactide bioplastic: characterization and biodegradability. Polym Degrad Stab 2009; 94: 1076-1084.

13. Alves C, Ferrão PMC, Silva AJ, et al. Ecodesign of automotive components making use of natural jute fiber composites. J Cleaner Prod 2010; 18: 313-327.

14. Saheb DN and Jog JP. Natural fiber polymer composites: a review. Adv Polym Technol 1999; 18: 351-363.

15. Bertoti AR, Luporini S and Esperidião MCA. Effects of acetylation in vapor phase and mercerization on the properties of sugarcane fibers. Carbohyd Polym 2009; 77: 20-24.

16. Chin C, Soykeabkaew N, Xiuyuan N, et al. The effect of fibre volume fraction and mercerization on the properties of all-cellulose composites. Carbohyd Polym 2008; 71: 458-467.

17. Mulinari DR, Voorwald HJC, Cioffi MOH, et al. Sugarcane bagasse cellulose/HDPE composites obtained by extrusion. Compos Sci Technol 2009; 69: 214-219.
18. Gu H. Tensile behaviours of the coir fibre and related composites after $\mathrm{NaOH}$ treatment. Mater Des 2009; 30: 3931-3934.

19. John MJ and Anandjiwal RD. Chemical modification of flax reinforced polypropylene composites. Compos Part $A$ 2009; 40: 442-448.

20. Araújo JR, Waldman WR and De Paoli MA. Thermal properties of high density polyethylene composites with natural fibres: coupling agent effect. Polym Degrad Stab 2008; 93: 1170-1175.

21. Luz SM, Del Tio J, Rocha GJM, et al. Cellulose and cellulignin from sugarcane bagasse reinforced polypropylene composites: effect of acetylation on mechanical and thermal properties. Compos Part A 2008; 39: 1362-1369.

22. Alvarez V, Rodriguez E and Vásquez A. Thermal degradation and decomposition of jute/vinylester composites. JTherm Calorim 2006; 85: 383-389.

23. Marques PAAP, Trindade T and Pinto Neto C. Titanium dioxide/cellulose nanocomposites prepared by a controlled hydrolysis method. Compos Sci Technol 2006; 66: 1038-1044.

24. Mulinari DR, Da Silva GLJP and Da Silva MLCP. Adsorção de íons dicromato nos compósitos celulose/ $\mathrm{ZrO}_{2} \cdot \mathrm{nH}_{2} \mathrm{O}$ preparados pelos métodos da precipitação convencional e em solução homogênea. Quím Nova 2006; 29: 496-500.

25. Mulinari DR and Da Silva MLC. Adsorption of sulphate ions by modification of sugarcane bagasse cellulose. Carbohyd Polym 2008; 74: 617-620.

26. Gushikem Y and Toledo EA. Preparation of coated cellulosic fiber (Surfactant Sciences Series). New York: Marcel Dekker, 1999.

27. Arrakhiz FZ, El Achaby M, Malha M, et al. Mechanical and thermal properties of natural fibers reinforced polymer composites: Doum/low density polyethylene. Mater Des 2013; 43: 200-205.

28. Arrakhiz FZ, El Achaby M, Benmoussa K, et al. Evaluation of mechanical and thermal properties of Pine cone fibers reinforced compatibilized polypropylene. Mater Des 2012; 40: 528-535.

29. Cerqueira EF, Baptista CARP and Mulinari DR. Mechanical behaviour of polypropylene reinforced sugarcane bagasse fibers composites. Procedia Eng 2011; 10: 2046-2051. 